Journal of Research in Interprofessional

Practice and

Education

Vol. 2.1

July, 2011
Journal of Research in Interprofessional Practice and Education (JRIPE)

Vol. 2.1

(c) 2011

Corresponding author: Lynda Weaver

Email: "LWWeaver@bruyere.orgi"

\section{Harnessing Complexity Science for Interprofessional Education Development: A Case Study}

\author{
Lynda Weaver, MHA, MEd; Angus McMurtry, LLB, PhD; \\ James Conklin, PhD; Susan Brajtman, RN, PhD; \\ Pippa Hall, MD, CFPC, MEd, FFPC
}

\begin{abstract}
Background: Developing learning activities for interprofessional education (IPE) with a group of stakeholders often involves negotiation, collectivity, creativity, innovation, and unpredictable results. Theoretical approaches that can explain and support such emergent processes are needed. This case study explored the applicability of complexity science to explain the experiences of committee members as they developed learning experiences for an IPE placement in a non-acute care hospital.

Methods and Findings: Data from a focus group with project steering committee members were re-analyzed through the lens of complexity science-specifically, three key principles of complex systems and five conditions for nurturing collective learning. Quotes were compared against each of these principles and conditions and, if there was a sufficient match, categorized accordingly into themes. These general themes were then sorted into clusters of sub-themes.

Conclusions: Complexity science provides a useful framework for understanding the open-ended, unpredictable, and innovative IPE development process analyzed in this article. It also offers helpful practical guidelines for future learning activity and curriculum development.
\end{abstract}

Keywords: Complexity science; Interprofessional education; Interprofessional placements; Curriculum

\section{Introduction}

Recent health reform in Canada has focused on the need for human resource enhancement. A key component of this enhancement is support for interprofessional teams $[1,2]$. Interprofessional health teams are particularly important in contexts like geriatrics, palliative care, and mental health, where patients typically have complex illnesses with multiple and compounded care needs. Nurses, physicians, pharmacists, therapists, and others on such teams require a holistic view of health; this means considering the needs of patients and families and including them as active participants in the decision-making process $[3,4]$.

These new developments in healthcare delivery have important implications for the education of health professionals [5]. Universities, colleges, and teaching hospitals have been challenged to provide preliscensure students with interprofessional education (IPE) experiences that enable them both 1) to learn about one another's roles, responsibilities, and potential contributions - in effect, bridging the professional "silos" that divide them-and 2) to interact in a "real life" setting with patients, their families, and the healthcare team. Developing the curriculum for IPE experi- 
101

Complexity science and IPE

Weaver, McMurtry, Conklin, Brajtman, Hall

Journal of Research in Interprofessional Practice and Education

Vol. 2.1

July, 2011 ences can be quite challenging, due to the novelty of the field, its cross-disciplinary influences, and its practical, real-life focus. One way that these IPE opportunities can be delivered is through interprofessional placements in teaching hospitals.

This article deals with the experiences of a committee that developed the curriculum for an interprofessional clinical placement within an urban, non-acute-care hospital. As we shall see, the curriculum development process was unusually openended, with a final product that emerged unpredictably through exploration, discussion, and negotiation among members of the committee. To better understand (albeit retrospectively) what happened during this process, as well as to identify practical guidelines or "lessons learned" for similar endeavours in the future, we chose to interpret the committee members' experiences through the lens of complexity science-an influential field theory devoted to studying and nurturing such seemingly chaotic learning processes. In recent years, complexity science has been taken up by a number of authors researching general education, healthcare education and practice, and interprofessionalism, specifically [5-11].

The article begins with an outline of the interprofessional education placement project and the curriculum development process. This is followed by a brief overview of complexity science and specific complexity principles pertinent to this case. Results from a focus group discussion with members of the curriculum development committee are presented to illustrate the applicability of each of these complexity science principles. The discussion section reflects on the fit between complexity science and the curriculum development process, and outlines lessons learned. In the conclusion, we argue that complexity science can provide not only a useful framework for understanding the current case, but also practical guidelines for future interprofessional curriculum development.

\section{Context}

IPE has been defined in the following way: "Interprofessional Education occurs when two or more professions learn with, from and about each other to improve collaboration and the quality of care" [12]. This may sound relatively straightforward, but the logistics, skills and willingness to comply to this way of teaching can actually be quite complex and contentious. Members of different professions come to the planning table with differing disciplinary paradigms and institutional backgrounds $[13,14]$. Seemingly simple planning and problem-solving processes can unfold in unpredictable, non-linear, and even anarchic ways as participants attempt to understand and negotiate different perspectives and priorities $[6,15]$.

In recognition of the importance of IPE, as well as its challenges, Health Canada provided major research funding in 2005 and again in 2006 to 20 projects across Canada to support the development of innovative educational initiatives (IECPCP) [16]. This article focuses on one of those research projects, implemented in an urban, non-acute care hospital from 2006 to 2008. It aimed to develop and evaluate an educational intervention-specifically, a learning module on interprofessional teamwork-for students of various health professions (nursing, medicine, physical therapy, pharmacy, etc.) who were coming to the hospital for their clinical place- 
Complexity science and IPE

Weaver, McMurtry, Conklin, Brajtman, Hall

Journal of Research in Interprofessional Practice and Education

Vol. 2.1

July, 2011 ments. The project, entitled Interprofessional Education Collaborative for PatientCentred Practice through the Humanities (IECPCP\&H), was overseen by an interprofessional steering committee and research staff. Committee members were recruited from hospital staff, patient and family representatives, and faculty and students from four local universities and colleges that educate health professionals. The research staff consisted of the three principal investigators $(\mathrm{PH}, \mathrm{LW}, \mathrm{SB})$ and three employees (manager, research associates).

The focus of this article is not the IECPCP\&H project as a whole. Rather, it focuses on one particular aspect of the project: the experiences of the steering committee during the curriculum development process. As we will show, this process was neither simple nor predictable. At the beginning of the process, the final product (i.e., the placement learning activity for health profession students) was not yet defined. Our intention was to have the steering committee and staff create the learning activity collaboratively. This open-ended approach was originally based on a combination of theoretical insights from adult education, social constructivism, community development, and reflective practice. The only constraints placed on the curriculum development process were that the final product had to 1) be short enough to be completed during an already busy placement, 2) be applicable to all levels of learners (from non-regulated positions to medical residents), and 3) require the learner to interact with patients and team members. We also stipulated that the activity contain an emphasis on the humanities in healthcare.

The steering committee met for approximately 90 minutes once a month for nine months. What emerged from this process was a self-learning module (a 90page paper booklet) for students to complete at their own pace during their placement. The module emphasized connecting with patients, including them as a vital part of the care team, and exploring the roles of all the professional team members. Learners were required to interact with individuals from professions other than their own and to reflect on their learning. After working through three sections, consisting of holistic care, interprofessional teamwork, and the humanities in healthcare, learners were invited to produce a creative summary of their learning experience, with the patient as the central focus. For example, learners created collages, essays, poems, and 3-D models representing their experiences. They were encouraged to work on these summaries with other students and, where appropriate, the patient and family members. Although the current article focuses on the curriculum development process rather than the results of the educational intervention (i.e., the self-learning module) on students, the intervention does appear to have been effective in achieving its objectives [17].

\section{Theoretical Framework}

Many established theories of curriculum development, such as Tyler's technicalrational approach, assume that educational goals can be settled in advance, predictably brought about through controlled inputs, and easily measured [18]. This sort of characterization did not, however, fit well with committee members' experiences of IPE curriculum development. Indeed, such technical approaches have been 
Complexity science and IPE

Weaver, McMurtry, Conklin, Brajtman, Hall

Journal of Research in Interprofessional Practice and Education

Vol. 2.1

July, 2011 critiqued by many educators [9] and would appear to be particularly ill-suited to IPE, characterized as it is by the dynamic interaction of differing perspectives and uncertain outcomes [8].

To retrospectively understand the steering committee's open-ended and loosely structured-but nonetheless effective-curriculum development process, the authors turned to a theory well suited to uncertainty, negotiation, and emergence: complexity science. Complexity science is a cross-disciplinary discourse that has developed over the last few decades to study complex systems. One of the best ways to define complex systems is to contrast them to merely simple or complicated systems. Although the terminology differs slightly, this classification of systems into simple, complicated, and complex is based on one originally identified by the physicist Warren Weaver in his seminal 1948 article entitled "Science and Complexity" [25].

Simple and complicated systems are phenomena-like rocks, machines, or gasses - that can be exhaustively studied through traditional analytic, mechanistic, and statistical means. This is because there is a predictable, proportional, and controllable link between causes and effects $[8,9]$. An example of a simple problem is fixing a tire; an example of a complicated problem, requiring more statistical analysis, would be sending a rocket to the moon [19].

Other phenomena-like the human brain, ecosystems, and the economy-resist such reductive analysis. Unlike the simple or complicated systems, these complex systems are characterized by non-linear patterns of organization $[10,20]$. This makes them inherently unpredictable, because small causes may produce large effects, and visa versa. One example of a complex problem-one that neither mechanistic nor statistical analysis could entirely "solve" - is raising a child [19].

Complexity science has been used to study a variety of topics related to the focus of this article, including psychological well-being [21], learning and classroom education [9], interdisciplinary knowledge [22], health care systems [23], and interprofessional health teamwork and education $[5,6,11,24]$. One of the main reasons why complexity is invoked as a theoretical framework in these contexts is its capacity to integrate uncertainty, dynamic interactions, the collision of multiple (often opposing) perspectives, and unpredictable, emergent outcomes. The specific principles of complexity that we will apply to the current case are listed below.

\section{Research Objectives}

As described above, we turned to the emerging science of complexity in the hope that it might offer a generative framework for analyzing the focus of this article: the perceptions of the interprofessional steering committee-made up of educators, practitioners, and patient/family representatives-on their experiences developing an IPE curriculum. Our intent was to analyze the previously recorded experiences of the focus group participants 1) to determine whether the development process can be understood as the unfolding of a complex system and 2) to reflect on how framing participants' experiences in this manner might yield lessons that could be useful for others engaging in similar exploratory, open-ended, interprofessional curriculum development efforts. 


\section{JRIPE}

104

Complexity science and IPE

Weaver, McMurtry, Conklin, Brajtman, Hall
Our criteria for determining the presence (or absence) of complexity in the curriculum development process involved three key principles characterizing emergent complex systems and five conditions for nurturing learning in such systems $[9,20,26]$ :

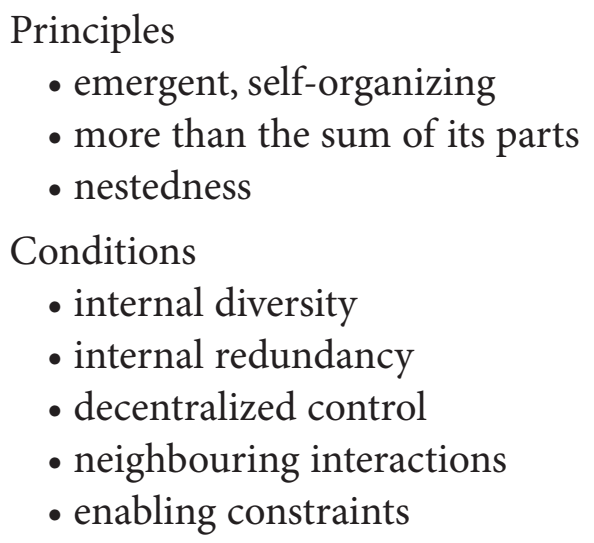

These principles and conditions are described in greater detail in the Results section, with each presented alongside concrete illustrations drawn from the focus group data.

\section{Methods}

Data were derived from a focus group conducted with members of the steering committee before the completion of the project. The focus of the group discussion was to better understand the participants' experiences during the curriculum development process. Receiving this information would enable the research staff to correct the project's faults, where needed, and to continue with what was working. Complexity science became known to one of the principal investigators (LW) after the project ended. We subsequently re-analyzed the focus group data through the lens of complexity science to determine whether the experiences of the committee members aligned with the principles and conditions of complexity science.

\section{Focus Group Methods}

The focus group was held nine months before the end of the IECPCP\&H project in October 2007. All steering committee members were invited to attend, as indicated on the consent forms they signed at the beginning of the project. The research staff did not attend the focus group to ensure the committee members could openly critique the project without constraint. A facilitator was hired to conduct the focus group (JC). In total, 10 of the 22 steering committee members participated, representing the university/college faculty, students, hospital staff, and patient/family members. Two data collection methods were employed. An administrative assistant from the hospital (not associated with the project) took notes of the discussion on a laptop computer, and the session was also audio-taped, with the participants' permission. The facilitator created a dense (but not verbatim) transcript (approximately 7,500 words), based on the word processing file and audiotape. The full transcript was not used as the basis for the complexity analysis, as it would be pos- 
Complexity science and IPE

Weaver, McMurtry, Conklin, Brajtman, Hall

Journal of Research in Interprofessional Practice and Education

Vol. 2.1

July, 2011 sible for the analyzer (LW) to identify who said what as she was familiar with all the steering committee members.

The facilitator then used a technique to extract codes and themes from the data based on analytical procedures recommended in many standard texts on qualitative methods [27-30]. After identifying exemplary themes, the facilitator reviewed the participant comments to select quotations that illustrated these themes. To guard against the possibility of selection bias, the facilitator used two procedures. First, all participant statements were subjected to the coding and theming process, and only three off-topic statements were excluded. Second, the facilitator illustrated each theme by including all of the associated quotations from the data set (with any identifying material removed). Thus, the data set that we used for the re-analysis included almost all participant statements from the focus group.

The facilitator produced a comprehensive 34-page report with his interpretation of the results, organized into categories according to the predefined questions: "What is working well?" "What changes should be made?" The report had two sections, one with highlights of the results and the other with details. In the detailed section, the facilitator sorted representative quotes into themes under each of the predefined questions. For our analysis, we treated the 87 separate quotations in the detailed section as in situ data about the experiences of these committee members in the development process, without concern for the facilitator's themes.

\section{Complexity Science Analysis}

A deductive content analysis of the data was performed [31]. The three principles and five conditions for emergent complex systems served as a predetermined categorization framework for the coding of the data [32]. Each quote was treated as the expression of one or more thoughts and informed as many categories during the coding process as seemed appropriate. One of the authors (LW) first read the quotes, comparing each one against each of the principles and conditions and, if there was a sufficient match, coding each quote accordingly. These general themes were then sorted into clusters of subthemes. This analysis was conducted with the guidance of another author (AM). The themes and subthemes were distributed to the rest of the writing team, all of whom agreed with the results.

Our analysis resembles a case study in that it is a bounded, single unit of analysis concerning a phenomenon we know little about [33], though we did not seek out multiple sources of data [34]. As Anderson, Crabtree, Steele, and McDaniel [35] point out, complexity science is well-suited to case study research if, instead of taking a mechanistic view of the entity under study, one focuses on better understanding the emerging patterns and relationships within an integrated system (in this case, within the process of developing an interprofessional curriculum).

\section{Results}

Table 1 shows the complexity science principles and conditions along with the subthemes that emerged from the analytical procedures. Each principle and condition is paired with representative quotes from the focus group discussion. Because of the 


\section{JRIPE}

106

Complexity science and IPE

Weaver, McMurtry, Conklin, Brajtman, Hall

possibility of identifying participants, the analyst was not privy to the participants' various roles on the committee (e.g., staff, professor, student, family representative).

Table 1

\section{Three principles of complexity science, five conditions, and theme headings that emerged from IECPCP\&H Steering Committee focus group analysis (number of quotes)}

\begin{tabular}{|c|c|c|}
\hline \multicolumn{3}{|r|}{ Sub-themes (number of quotes) } \\
\hline & $\begin{array}{l}\text { Principle 1: } \\
\text { Emergent, self-organizing } \\
\text { (19) }\end{array}$ & $\begin{array}{l}\text { a. Confusion \& uncertainty at first, then clarity (9) } \\
\text { b. Formed as a group (7) } \\
\text { c. Stimulating company and content (3) }\end{array}$ \\
\hline & $\begin{array}{l}\text { Principle 2: } \\
\text { More than the sum of its } \\
\text { parts (9) }\end{array}$ & $\begin{array}{l}\text { a. Collaboration = momentum, creativity, collective learning (4) } \\
\text { b. Potential to make changes in health care (3) } \\
\text { c. Synthesis of what was generated at the meetings (1) } \\
\text { d. Struggle of going from theory to practice is good, challenging } \\
\text { - challenge begets change (1) }\end{array}$ \\
\hline & $\begin{array}{l}\text { Principle 3: } \\
\text { Nestedness (22) }\end{array}$ & $\begin{array}{l}\text { a. Need to make connections with relevant external groups: schools, Health Canada, } \\
\text { Ministry of Education, Ministry of Health, Patient Safety (7) } \\
\text { b. Ideas to move project forward (6) } \\
\text { c. Difficulty connecting with/influencing relevant external groups (4) } \\
\text { d. Potential problems sustaining project (2) } \\
\text { e. Implementation of project (2) } \\
\text { f. Need for internal education activities (1) }\end{array}$ \\
\hline & $\begin{array}{l}\text { Condition 1: } \\
\text { Internal diversity (11) }\end{array}$ & $\begin{array}{l}\text { a. Challenges in having a full range of diversity on committee (8) } \\
\text { b. Interprofessional leadership (1) } \\
\text { c. Bilingualism (1) } \\
\text { d. In praise of various members(1) }\end{array}$ \\
\hline & $\begin{array}{l}\text { Condition 2: } \\
\text { Internal redundancy (9) }\end{array}$ & $\begin{array}{l}\text { a. New/changing members reduced commonalities among members (5) } \\
\text { b. Collaboration was rewarding ( } 3 \text { ) } \\
\text { c. Sense of cohesiveness floundered toward the end ( } 1 \text { ) }\end{array}$ \\
\hline & $\begin{array}{l}\text { Condition 3: } \\
\text { Decentralized control (10) }\end{array}$ & a. All opinions were valued (10) \\
\hline $\begin{array}{l}\text { Journal of Research in } \\
\text { Interprofessional }\end{array}$ & $\begin{array}{l}\text { Condition 4: } \\
\text { Neighbouring interactions } \\
\text { (25) }\end{array}$ & $\begin{array}{l}\text { a. Would have liked even more meetings/interactions/assignments (5) } \\
\text { b. Challenges getting to meetings or getting information (5) } \\
\text { c. Challenges with understanding some ideas (4) } \\
\text { d. Ideas/creativity were welcomed ( } 3 \text { ) } \\
\text { e. Hoping that project affects students, staff, families, schools (3) } \\
\text { f. Need to keep getting the word out about the project (3) } \\
\text { g. Different perspective due to interacting together (1) } \\
\text { h. Module led to some immediate action (1) }\end{array}$ \\
\hline $\begin{array}{l}\text { Practice and } \\
\text { Education } \\
\text { Vol. } 2.1 \\
\text { July, } 2011\end{array}$ & $\begin{array}{l}\text { Condition 5: } \\
\text { Enabling constraints (9) }\end{array}$ & $\begin{array}{l}\text { a. Structure kept us going (5) } \\
\text { b. Meetings were well organized (3) } \\
\text { c. D’Amour \& Oandasan model is useful (1) }\end{array}$ \\
\hline
\end{tabular}




\section{JRIPE}

107

Complexity science and IPE

Weaver, McMurtry, Conklin, Brajtman, Hall

Journal of Research in Interprofessional Practice and Education

Vol. 2.1

July, 2011
Journal of Research in Interprofessional Practice and Education

However, the focus group facilitator confirmed that a representative variety of roles and disciplines were represented in the quotations.

Some quotes fit under both a principle and a condition, whereas others were specific to just one. This multiple coding is not surprising as the principles and conditions are interdependent ideas that cannot be, nor should they be, easily separated $[26,35]$. This observation, in itself, is an indication of complexity-ideas (principles) are interdependent with actions (conditions) [35].

\section{Principle 1: Complex systems are emergent and self-organizing}

Three principles of complex systems in particular seemed to apply to the current case. The first is that a complex system emerges in a bottom-up manner, through interactions among its component parts (or agents). Since there is no central planner or general instructions in this process, complex systems are typically described as self-organizing or as balancing between order and disorder [9,20]. Applied to the current context, this principle suggests that interactions among individuals gave rise to coherent but dynamic and unpredictable group identities and norms. For instance, one might expect to see shifting leadership among members as differing sorts of expertise are required.

In all, 19 quotes fit under this principle, and three sub-themes emerged. The following quote illustrates the confusion that this self-organizing process caused at first, as well as the coherence that emerged as we progressed:

I remember thinking, especially throughout the initial meetings, that it was confusing. At the beginning, trying to see what you were supposed to be doing, and what we all were supposed to be doing together, was confusing. And I wondered how it was going to come together. But I think it was the nature of the process, starting from scratch, trying to put together a whole curriculum, so it began with a lot of ideas floating around. In the early stages, I had a hard time imagining what was going to come from this. But then you could see everything come together at the end.

In sub-theme 1a: Confusion and uncertainty at first, then clarity

Several participants felt that they were part of an emerging group that functioned well together.

Seven quotes make up this sub-theme, including the following:

I found it very interesting because of how everyone has come together. In other words, exemplifying what the idea is in the first place. Collaboration. It is very inclusive.

\section{In sub-theme 1b: Formed as a group}

Some participants were pleased with the open-ended nature of the meetings and the multiple sorts of perspectives expressed. This next quote illustrates how this environment was stimulating for some committee members, adding to the emergent, self-organizing nature of the process: 
Complexity science and IPE

Weaver, McMurtry, Conklin, Brajtman, Hall

Journal of Research in Interprofessional Practice and Education

Vol. 2.1

July, 2011
Journal of Research in Interprofessional Practice and Education

I found the meetings themselves rewarding. The project offered me a different way of looking at the patients. It was a nice reminder to me, as though I was already learning from the curriculum.

In sub-theme 1c: Stimulating company and content

\section{Principle 2: Complex systems are more than the sum of their parts}

A second principle is that a complex system is more than the sum of its parts. This is because the dynamic relationships between the system's parts are as important as the parts themselves [26]. Complex systems thus embody possibilities for action not present in their components-the way, for example, a human being has possibilities for action that go beyond those of a simple aggregation of bodily organs. This principle can also be applied to human collectives: It suggests that when people and ideas are brought together in an emergent group, possibilities for doing and knowing are expanded. From the perspective of educators and others concerned with the phenomenon of learning, complex systems' adaptive, self-organizing qualities mean that they can be understood as learning systems [9]. Knowledge is therefore not seen as limited to individual brains; it is also enacted and embodied in the relational, networked activities of complex "learning" systems that emerge at multiple biological and cultural levels.

The nine quotes coded under this principle show how members of the team were able to synergistically build upon one another's contributions and co-create something new-something that may not have existed had they not been brought together. The two representative quotes below show that, as an interprofessional team, they were better equipped to address the job they had been asked to perform than if each one had tackled it without discussion with others.

I found the collaboration, and the momentum that it fostered, to be rewarding. As new people came on board and learned, collaboration was modeled for everyone. People embraced that collaborative model. And tremendous momentum was gathered.

In sub-theme 2a: Collaboration consists of momentum, creativity, collective learning

I appreciated-and this is a little tongue in cheek-the opportunity to become immortal. Because I think we have had the opportunity to have a profound effect on what will eventually be the patients' level of care. I think that doctors and nurses and administrators and others in the future are all going to change the world, based on what all of us contributed. I find that mind-blowing, it is almost as if we have shifted the world a little. My whole life has been spent trying to look after people, and this project has meant the most to me, of it all.

\section{In sub-theme 2b: Potential to make changes in healthcare}

One person talked about the research staff's ability to make good use of the steering committee's input by further developing ideas that were generated at the meetings (sub-theme 2c: Synthesis of what was generated at the meetings). Another 
Complexity science and IPE

Weaver, McMurtry, Conklin, Brajtman, Hall

Journal of Research in Interprofessional Practice and Education

Vol. 2.1

July, 2011 person's thinking indicated that making the project into something greater than the sum of its parts was challenging, but the struggle was worthwhile.

But the strength is really that the overall concept of the project challenged you to go from a theoretical to a practical construct. ... it is really trying to get the students to think on a completely different level, and that happens when you are challenged. So trying to integrate the humanities and its pillars is complex, and it challenged us and the students to think on a different level. I think that struggle is good sometimes in education. If it is too easy, it does not do the job.

$$
\text { (In sub-theme 2d: Challenge begets change) }
$$

\section{Principle 3: Complex systems are characterized by nestedness}

The third important principle relevant to the current case relates to the nested relationships among complex systems. Complex systems are typically open systems-that is, they interact with their environment [20]. It should be emphasized that although complex systems are inextricably linked to their environments and dependent on them, they are never determined by them. As mentioned above, complex systems' behaviour is governed by their own self-organizing, non-linear internal structures and thus cannot be reduced to, or understood in terms of, straightforward causal inputs and outputs.

Furthermore, complex systems are often ecologically nested, in the sense that they both form part of larger complex wholes and are themselves composed of smaller-scale systems. In human beings, for instance, cells and organs can be seen as nesting within the human body as a complex whole; and the human body can, in turn, be seen as nesting within larger social, physical, and biological systems [36]. In the current context, this principle can be seen as articulating a dynamic, ecological framework for understanding the interactions among participating individual professionals, work groups, and larger institutional or organizational bodies. Each level is connected but still has some degree of autonomy.

Six sub-themes were apparent from the 22 quotes falling in this theme. They represent the ecological relationship between the project and the wider systems in which it is nested, such as the teaching hospital, the education system, and the two provincial ministries that affect healthcare education. This is the largest grouping of quotes, showing that it was an important topic for the steering committee. Members were particularly concerned with the sustainability of the project, since they had worked hard to bring it to fruition and believed in its value for the healthcare system. They also hoped that the new curricula might be integrated into the broader social and professional environment.

Seven quotes related to the need to work closely with influential groups to ensure the project's sustainability. They illustrate the participants' viewpoints, as well as the variety and complexity of the nested, mutually affective systems involved.

I think there is a strong link between this interprofessional model and patient safety. It may not be a direct link, but, indirectly, with better collaboration between providers, you will get better quality of care.

(In principle sub-theme 3a: Need to make connections with relevant external groups) 
Complexity science and IPE

Weaver, McMurtry, Conklin, Brajtman, Hall

Journal of Research in Interprofessional Practice and Education

Vol. 2.1

July, 2011
Journal of Research in Interprofessional Practice and Education

Six quotes show that the group was thinking of ways to disseminate news about the project to the other systems in which it was nested.

The whole dissemination of the model, presenting at conferences.... It could be a poster, it could be a session. This project should blow its horn, create disciples all over the place to spread the gospel.

(In principle sub-theme $3 b$ : Ideas to move project forward)

Four quotes pertain to the problems that are or might be encountered when trying to influence other systems. For instance, one member said,

What will make it happen is bringing in the key stakeholders, but even then just to get the message out is a huge task. People are busy, and the systems are such that this is not the only thing on the block; in fact, the block has so much going on that you cannot see the block.

(In principle sub-theme 3c: Difficulty connecting with/influencing relevant external groups)

Three other subthemes emerged under this principle, one related to potential problems sustaining the project (sub-theme $3 \mathrm{~d}$ ), one related to the need for internal education to promote the project (sub-theme $3 \mathrm{f}$ ), and one related to how a project can or cannot be implemented (sub-theme $3 \mathrm{~d}$ ):

In the hospital, there are lots of projects that get initiated that are never implemented. The literature says you have about a $70 \%$ failure rate with projects. Lots of projects are developed but not effectively implemented. One satisfactory thing here is that you see it being implemented. And it happened within a short period of time, relative to other projects that take years.

\section{Condition 1: Emergent collective systems require internal diversity}

In addition to the three principles, we viewed the collected data through the lens of five complexity-inspired conditions for nurturing collective learning. These conditions were first articulated by Davis and Simmt [38] and subsequently elaborated by, among others, Davis and Sumara [9], Davis, Sumara, and Luce-Kapler [7], and McMurtry [8]. They are not intended as rigid rules. Rather, the conditions are meant to provide useful guidelines for those involved in developing educational experiences. Most seek simply to harness, for productive educational purposes, the interpersonal dynamics that occur within any human collective.

The first condition, diversity among the agents within a complex system, is crucial to learning and innovation. It is the source of a system's intelligence, that is, its ability to respond appropriately and creatively to changing circumstances. In the context of human collectives, diversity "expands a group's set of possible solutions and allows the group to conceptualize problems in novel ways" [38, p. 36]. Roles may be assumed, but they should be flexible and reflective of changing situations and members' special talents. 
111

Complexity science and IPE

Weaver, McMurtry, Conklin, Brajtman, Hall
Journal of Research in Interprofessional Practice and Education

Vol. 2.1

July, 2011
Journal of Research in Interprofessional Practice and Education

This theme had 11 quotes divided into four sub-themes. The following quote shows that the group was conscious of the need for diversity and that they did not always achieve it.

It would have helped to have more representatives from the humanities. Where were the folks from literature? I think they would have more to offer. We talk about these things, but we had no profound grasp of the subject.

(In condition sub-theme 1a: Challenges in having a full range of diversity on committee)

One participant said that the leadership of the steering committee modeled good diversity and was beneficial for the project (condition sub-theme 1b). Another was pleased that the group conducted all its work in both languages, something that was necessary, challenging, and rewarding (sub-theme condition 1c). Diversity has the benefit of bringing together people well-suited to the job.

I think the personalities of the people, they are great people. [Name] is very intelligent and passionate and sensitive and concerned, and the same with [Name]. They have a lot of energy.

(In condition sub-theme 1d: In praise of various members)

\section{Condition 2: Emergent collective systems require internal redundancy}

The complement to diversity is redundancy. Some redundancy, or duplication, is necessary within a complex system because it provides the common ground on which agents interact. In the context of human collectives, it refers to the shared subject matter, language, culture, history, or training that helps a group to "gel," work together productively, and establish a common purpose. Such commonality also makes a system more robust, since it allows agents to compensate for one another's lapses.

Three subthemes clustered within this condition concerning redundancy. As people came and went on the steering committee, commonality within the group was sometimes disrupted.

People would delegate their participation to someone else in their department, and that really did not help the group process.

(In condition sub-theme 2a: New/changing members reduced commonalities among members)

The collaborative culture nurtured within the group was another form of helpful redundancy.

I found the collaboration, and the momentum that it fostered, to be rewarding. As new people came on board and learned, collaboration was modeled for everyone. People embraced that collaborative model. And tremendous momentum was gathered.

(In condition sub-theme 2b: Collaboration was rewarding)

As the project came closer to ending, it appeared that the research staff could have 
Complexity science and IPE

Weaver, McMurtry, Conklin, Brajtman, Hall

Journal of Research in Interprofessional Practice and Education

Vol. 2.1

July, 2011

\section{Journal of Research in Interprofessional Practice and Education}

done a better job of maintaining communications. As a result, the sense of commonality within the steering committee wavered:

Just recently, it seems that the project has reached a point where the steering committee is not sure whether we are coming back, whether we are still involved. Are we going home? The project has gone one way, and we are still here. The project is supposed to go into next year, and I cannot see that. They are in limbo, the project goes one way and we are feeling separated already, at the end.

(In condition sub-theme 2c: Sense of cohesiveness floundered toward the end)

\section{Condition 3: Emergent collective systems require decentralized control}

As described above, complex systems emerge in a bottom-up or grassroots manner, rather than through centralized or external control. This does not mean that they are disorganized; instead, they are self-organized through the interactions of the systems' component parts or agents, with all having some sort of input. Such decentralized structures allow innovation to emerge [39]. In human collectives, this means ensuring both that coherent decisions and actions are taken, and that responsibility for taking them is shared among participants.

A conscious effort was made by the project staff to ensure that the interprofessional approach to project management was non-hierarchical and that each person was there for a purpose. The 10 quotes in this subtheme pertain to the participants' appreciation of the decentralized, equalized nature of the group.

I felt that the project team showed us that they had the values of interprofessionalism. If, at the end of a meeting, I was wondering what they would do with the ideas and suggestions that had been mentioned, I trusted the project team because they showed that they also felt some uncertainty. I knew that they would collaborate with us, and that if something wasn't clear they would bring it back to us. The glue that kept us together in the right direction was that they would come back to us. If we had had more directive or structured leaders, we might have felt momentarily reassured, but we would not have had the sense of them wanting to create with us. The normal, structured way narrows down the possibilities to create and explore.

One thing I found was that everybody was so receptive to everything. There was no sense of being patronized, no defensiveness, patronization.... The reception was wonderful.

(In condition sub-theme 3a: All opinions were valued)

\section{Condition 4: Emergent collective systems require neighbouring interactions}

Agents within a complex system need to be able to interact and influence one another. In the context of knowledge-oriented human collectives, it is not so much 


\section{JRIPE}

113

Complexity science and IPE

Weaver, McMurtry, Conklin, Brajtman, Hall
Journal of Research in Interprofessional Practice and Education

Vol. 2.1

July, 2011
Journal of Research in Interprofessional Practice and Education

people's physical bodies that need to interact as their ideas and interpretations. When diverse ideas and expertise are allowed to interact, participants' understandings can be enriched and the horizon of possible solutions can be widened.

This condition had the largest number of quotes assigned to it, 25 in all. Eight sub-themes were created, illustrating the various challenges involved in creating neighbouring interactions. One sub-theme shows that some committee members would have liked even more opportunities to provide input to the project and interact with others. For instance:

I would have liked to meet twice a month. A lot of the time we had not finished discussing what we wanted to and we knew that we would not be seeing each other for a month.

(In condition sub-theme 4a: Would have liked even more meetings/interactions/assignments)

Five people expressed their challenges maintaining contact with the group, either because they could not easily get to the meetings or because they did not have full access to distribution systems. One participant, for example, observed:

It was difficult to attend meetings due to scheduling. There was talk for a while about integrating a virtual and Internet communications system, but that was maybe beyond what we could do this time.

(In condition sub-theme $4 b$ : Challenges getting to meetings or getting information)

Four other quotes indicated that we might have done a better job illustrating the purpose and need for certain ideas, especially around the humanities. The ideas needed more opportunities to interact and mature.

The part applying the humanities was less rewarding because it was harder to deal with, and working through the interprofessional issues was important and more grounded in peoples' experiences. There was less time to take on the question of the humanities, and it was therefore less successful, less rewarding. I found it more interesting to work through the interprofessional part.

(In condition sub-theme 4c: Challenges with understanding some ideas)

Three other people talked about the value of hearing each others' ideas: I always loved being involved in intelligent and informed discussion, and these conversations were great. With everybody's skills and background, I couldn't wait to get here.

(In condition sub-theme 4d: Ideas/creativity were welcome)

Another three people talked about their wishes for this project to interact with other systems, such as the learners, the hospital staff, the families of patients, and the schools where learners are educated. 
Complexity science and IPE

Weaver, McMurtry, Conklin, Brajtman, Hall

Journal of Research in Interprofessional Practice and Education

Vol. 2.1

July, 2011
Journal of Research in Interprofessional Practice and Education

The interprofessional nature of the program really challenged the organization, because our learning programs tend to focus on specific disciplines. There is not a lot of cross-talk between disciplines. We heard this from the students at the table. That is part of the challenge here. We have to change how we conduct our education activities in this organization. It has to become interprofessional.

(In condition sub-theme 4e: Hoping that project affects students, staff, families, schools)

Three other quotes addressed the need for neighbouring interactions to continue in order for people to hear about and adopt the module.

Another way to alleviate the complexity of the communication task would be to establish an interprofessional educational centre at these health care facilities where the modules will be used, and we need the same thing at the colleges and universities. This would get us out of the individual silos, and would provide a single group on which to focus communications.

(In condition sub-theme 4f: Need to keep getting the word out about the project)

The last two subthemes in this condition pertain to one person obtaining a different perspective due to interacting with others (condition sub-theme $4 \mathrm{~g}$ ) and another person saying that the module led to some immediate action (condition sub-theme $4 \mathrm{~h}$ ).

It is going well because they have students going through the modules this summer and fall. They did some sessions here and at another site.... They actually took actions to push the project ahead. They did the action part of it. We could see results right away.

(In condition sub-theme 4h: Module led to some immediate action)

\section{Condition 5: Emergent collective systems require enabling constraints}

This final condition for nurturing collective learning involves finding a productive balance between, on the one hand, the rules or boundaries necessary to orient and sustain the coherence of a complex system, and, on the other, sufficient openness for diversity to express itself and for the system as a whole to develop in innovative and unpredictable ways. The approach is similar to that of a soccer or basketball game where the rules-although constraining-enable the emergence of dynamism, creativity, and diversity. In knowledge-oriented groups, this might mean putting procedures in place to ensure that all members get a chance to speak, and that decisions pertaining to a particular topic are reached within a reasonable amount of time-but without in any way prejudging or predetermining what those decisions might be.

Three sub-themes were formed out of the nine quotes that fell within this condition. First boundaries were set, but members were encouraged to try anything within those boundaries. 
Complexity science and IPE

Weaver, McMurtry, Conklin, Brajtman, Hall

Journal of Research in Interprofessional Practice and Education

Vol. 2.1

July, 2011
Journal of Research in Interprofessional Practice and Education

We do need some boundaries, to give some continuity and structure, and to me this was provided by their values, and by the way we could express ourselves in our language and with emails. I thought that somehow there is structure there, and they knew where it was going.

We took a very abstract idea of what we were going to do and achieve in terms of developing a learning model and a program of champions, and the team has systematically taken us through the steps and facilitated that process. In a very positive, endorsing, empowering and facilitative way. And so I am very pleased with how the process unfolded. Clearly it is a very supportive process, and hopefully it is a sustainable process.

(In condition sub-theme 5a: Structure kept us going)

Constraints were also apparent in the form of ensuring the meetings were well organized.

I was very impressed. I did not think it would be so well organised. I enjoyed working, dealing with all the members.

(In condition sub-theme 5b: Meetings were well organized)

One person mentioned that an appropriate enabling constraint for the project's tasks would be to use the D'Amour and Oandasan model [40] to guide us. This model was put forth in 2005 to conceptualize the context that must be recognized if interprofessionalism is to be integrated into the educational and practice environments. It outlines the full scope of the educational and practice environments, the stakeholders in each, and the expected outcomes from interprofessional cooperation.

\section{Limitations}

This case study is not without its limitations. Our results are from one case of a curriculum development process, reflecting one group's perceptions of the members' experiences from one source. Two limitations emerge from this situation. The first is internal validity. If we had access to more data on this group for triangulationsuch as the steering committee's own reflections of their experience through the lens of complexity science-our conclusions may have been different. The second limitation involves external validity. If we had examined other projects mandated to develop interprofessional curriculum, we may or may not have found the same fit with complexity science. In this case, the leadership was intent on establishing equality among its members, fostering creativity, and trusting the process to culminate in something not well-defined at the beginning.

The retrospective analysis of the focus group report presents another limitation. Had we started the project with complexity science in mind, we may have found different results-either a closer tie to complexity science or more disparity. Our analysis of this one case of curriculum development is an example of complexity science in action, and may not be suitable to all such occasions. 
Complexity science and IPE

Weaver, McMurtry, Conklin, Brajtman, Hall

Journal of Research in Interprofessional Practice and Education

Vol. 2.1

July, 2011
Journal of Research in Interprofessional Practice and Education

\section{Discussion}

The interprofessional curriculum committee was formed with the intention of fostering openness, interaction, and the emergence of new ideas. The committee members and research staff were not aware of complexity science during the development process. This science has, however, shown itself to be a useful framework for explicating the unpredictable and creative process of developing an interprofessional learning curriculum. Through a retrospective analysis, we found significant evidence in support of the idea that the development process could be understood as the unfolding of a complex system. The process aligned well with three key principles of complex systems: it emerged unpredictably in a self-organizing, nonhierarchical manner; it produced team knowledge that was more than the sum of its parts; and it was nested in an ecological, mutually-affective relationship with other systems.

Perhaps most importantly, the five conditions for emergent collective learning provide concrete guidance as to what worked well within the design team and how it might have worked better. The first condition, internal diversity, prompted us to more carefully consider the composition of the committee. While several members lauded the diversity present (for example, faculty members, hospital representatives, family members), others pointed to the lack of representatives from the humanities and student groups. It is possible, of course, that a committee can become too large and thus unwieldy or ineffective at getting its tasks completed. The concept of wieldiness [41] may help in such situations, as it prompts one to explicitly balance inclusiveness with the need to keep membership to a manageable number.

The next condition, internal redundancy, highlighted the need for committee members to have sufficient opportunity (time, space, etc.) to develop commonalities such as trust and group culture. One important insight linked to this condition was the need for some duplication. For instance, if someone cannot attend all the meetings, the designated replacement must be up to date on the committee's purpose and work. Without this redundancy, group cohesiveness and the creative process may be fractured.

The third condition, decentralized control, provided a novel way to think about group processes that avoided the extremes of both strict, hierarchical control and "anything goes" disorganization. The fourth, neighbouring interactions, offered a helpful lens for understanding a large number of committee members' quotes. For example, it helped articulate the need for committee members to meet regularly, share ideas, and have some ongoing means for distributing ideas and information. Finally, the fifth condition, enabling constraints, provided a framework for understanding how one can structure group processes in a way that both sets boundaries to focus participants' activities and provides enough openness for creative solutions to emerge.

In Table 2, we outline lessons learned from our retrospective analysis of the committee's curriculum development process. Practical guidelines are provided for enacting each of the conditions for nurturing collective learning. Although these guidelines were developed in the context of a specific interprofessional curriculum 


\section{JRIPE}

117

Complexity science and IPE

Weaver, McMurtry, Conklin, Brajtman, Hall
Journal of Research in Interprofessional Practice and Education

Vol. 2.1

July, 2011 development process, we believe they may offer assistance to others (and to ourselves) engaged in similarly open-ended, collaborative group processes.

One theme that is not explicitly described in these principles and conditions is leadership. Taking on a project with the intention of it being non-hierarchical, nonlinear, and emergent may be daunting for a project leader. When power is decentralized, a different sort of leadership style is required [42-44]. For example, the leader must trust that the process will result in a quality product-that cohesion will emerge from chaos. Trust must also be placed in the group's expertise; the leader needs to give ownership of the product to the group members (who have been carefully selected). However, a fine balance is required. The group may not be able to finish selecting and polishing their contending ideas and concepts in the meetings. It may therefore be up to the leader to develop a draft document outside the meeting and bring it back to the group for review. Finally, the leader needs to help keep the group on track-in complexivist terms, sustaining the enabling constraints. This can mean keeping an eye on the time commitments and monitoring progress, while at the same time being aware of and faithful to group members' needs and goals.

Table 2

\section{Guidelines for harnessing complexity science's conditions for nurturing collective learning}

\begin{tabular}{|l|l|}
\hline $\begin{array}{l}\text { Condition for nurturing } \\
\text { collective learning: }\end{array}$ & How to harness these conditions for curriculum development \\
\hline $\begin{array}{l}\text { Internal } \\
\text { diversity }\end{array}$ & $\begin{array}{l}\text { - Are the right content experts on the team (clinicians, family members, patient } \\
\text { representatives, etc.)? }\end{array}$ \\
\hline $\begin{array}{l}\text {-Are the right process experts on the team (administrators, students, professors, } \\
\text { etc.)? }\end{array}$ \\
\hline $\begin{array}{l}\text { Internal } \\
\text { redundancy }\end{array}$ & $\begin{array}{l}\text { - Explain and express the commonalities of the group. Help them see their overlap- } \\
\text { ping experiences, concerns, expertise, needs and wishes. } \\
\text { Provide sufficient opportunity (time, space, etc.) to develop commonalities such } \\
\text { as trust and group culture. } \\
\text { - Consider the need for some duplication of roles, in case committee members are } \\
\text { ever absent. }\end{array}$ \\
\hline $\begin{array}{l}\text { Decentralized } \\
\text { control }\end{array}$ & $\begin{array}{l}\text { - Leaders ask questions and converse with the group to develop answers. } \\
\text { Expect and nurture creative, unforeseen possibilities/solutions. }\end{array}$ \\
\hline $\begin{array}{l}\text { Neighbouring } \\
\text { interactions }\end{array}$ & $\begin{array}{l}\text { - Content of the meetings should allow small groups to create and then to share } \\
\text { their ideas and expertise. } \\
\text { - Keep the group informed between meetings if needed. } \\
\cdot \text { Stay in touch with the group until the end of the project. }\end{array}$ \\
\hline $\begin{array}{l}\text { Enabling } \\
\text { constraints }\end{array}$ & $\begin{array}{l}\text { - Meetings should be short and productive, and as often as necessary. } \\
\text { Provide broad criteria for the outcome (curriculum being developed), and ask for } \\
\text { all options within those criteria. } \\
\text { product will eventually emerge. }\end{array}$ \\
\hline
\end{tabular}


Complexity science and IPE

Weaver, McMurtry, Conklin, Brajtman, Hall

Journal of Research in Interprofessional Practice and Education

Vol. 2.1

July, 2011

\section{Journal of Research in Interprofessional Practice and Education}

Additionally, it may be necessary to help faculty members and others responsible for curriculum renewal understand the usefulness of complexity science as a framework for project planning. Initiatives to create this new capacity within faculty members could be based on the five conditions for nurturing complex learning and could model the process of learning through a complex adaptive system.

\section{Conclusions}

The open-ended approach used by the committee for interprofessional curriculum development departed significantly from tradition. Instead of control and predictability, the process was characterized by diversity, non-linearity, collaboration, negotiation, innovation, and surprise. This approach is becoming more common in education [7], business organizations [38,39,45], and psychology [21]. It also seems well-suited to dynamic and cross-disciplinary contexts like IPE.

New conceptual models are needed to both understand and more effectively nurture these sorts of open-ended, emergent approaches. Complexity science offers one useful and widely recognized framework for doing so. In this article, we applied a complexity science approach to studying the process of developing of an interprofessional curriculum for pre-licensure health professions students in a teaching hospital. We found that complexity science provided a vocabulary and conceptual framework for understanding how this process unfolded, as well as what did and did not work in this process. Furthermore, it offered practical guidelines-"conditions for nurturing collective learning" - that could be employed in similar contexts.

If we undertake a similar curriculum development process in the future, we intend to explicitly invoke the principles and conditions of complexity with committee members. For example, we would articulate how the balance between openness and constraints is deliberate and intended to support the emergence of innovative solutions. We would also reassure participants that the difficulty they face in negotiating various perspectives is normal, acceptable, and-perhaps most importantly-a resource for creativity.

In a complex and evolving world, identifying the knowledge that students need to learn is never a simple task, especially within interprofessional contexts. We believe that the open-ended curriculum development process used in the current case is better suited to this complex reality than traditional linear approaches. However, we have to acknowledge that knowledge, like the world itself, is a moving, evolving target. The curricula we develop, though helpful to those we serve, can only be a temporary coherence. Others in the future will create other useful and coherent approaches-and that is something to be welcomed.

\section{Acknowledgements}

We would like to acknowledge Health Canada for the IECPCP grant that allowed us to develop the self-learning module. 
JRIPE

119

Complexity science and IPE

Weaver, McMurtry, Conklin, Brajtman, Hall

Journal of Research in Interprofessional Practice and Education

Vol. 2.1

July, 2011

\section{References}

1. Herbert, C.P. (2005). Changing the culture: Interprofessional education for collaborative patientcentred practice in Canada. Journal of Interprofessional Care, 19(S1), 1-4.

2. Romanow _BJ__(2002)._Building_on_Values:_The Future_of_Health Care in Canada. URL:

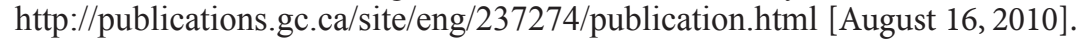

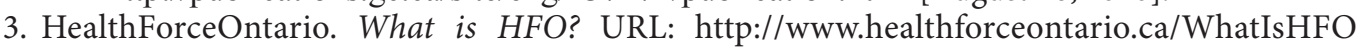
'AboutInterprofessional_Care.aspx:!' [March 16, 2011].

4. Interprofessional Care Steering Committee. (2007). Interprofessional Care:_A_Blueprint_for_Action,

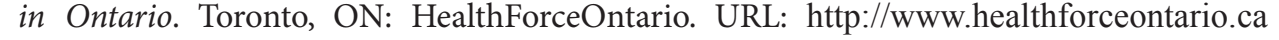

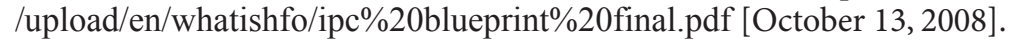

5. Bleakley, A. (2010). Blunting Occam's razor: Aligning medical education with studies of complexity. Journal of Evaluation in Clinical Practice, 16, 849-855.

6. Cooper, H., Braye, S., \& Geyer, R. (2004). Complexity and interprofessional education. Learning in Health and Social Care, 3(4), 179-189.

7. Davis, B., Sumara, D., \& Luce-Kapler, R. (2008). Engaging minds: Changing teaching in complex times, 2nd edition. New York: Routledge.

8. McMurtry, A. (2008). Complexity Theory 101 for educators: A fictional account of a graduate seminar. McGill Journal of Education, 43(3), 265-281.

9. Davis, B., \& Sumara, D. (2006). Complexity and education. Marwah, NJ: Lawrence Erlbaum.

10. Lambert, R., Brown, C., \& Bogg, J. (2007). Health and complexity. In Bogg, J., \& Geyer, R. (Eds.), Complexity, science and society. (pp. 51-53). New York: Radcliffe.

11. McMurtry, A. (2010). Complexity, collective learning and the education of interdisciplinary health teams: Insights from a university-level course. Journal of Interprofessional Care, 24(3), 217-219.

12. Centre for the Advansement_of Interprofessional Education (CAIPE). (2002). Defining IPE. URL:

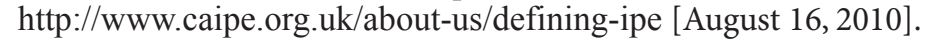

13. Hall, P. (2005). Interprofessional teamwork: Professional cultures as barriers. Journal of Interprofessional Care, 19(S1), 188-196.

14. Beattie, A. (1995). Troubled times: War and peace among the health tribes. In Mackay, L., Soothill, K., \& Webb, C. (Eds.), Interprofessional relations in health care. (pp. 11-26). London: Edward Arnold.

15. Opie, A. (1997). Teams as author: Narrative and knowledge creation in case discussions jn_multi-

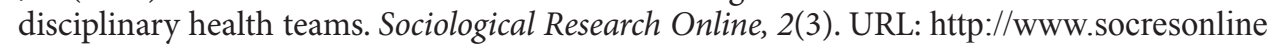
1.org. uㅡ/2/3/contents.htmli [January 5, 2007].

16. Health Canada. (2009), Interprofessional_Education_for_Collaborative Patient-Centred Practice

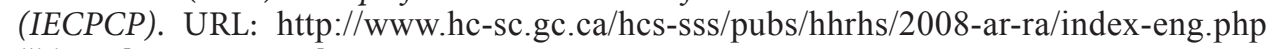

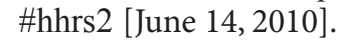

17. Hall, P., Weaver, L., \& Brajtman, S. (2006, June-2008, June). Interprofessional education for collaborative person-centred practice through the humanities, Final report, June 2006 - June 2008. Ottawa, ON: Bruyère Continuing Care.

18. Auger, W.F., \& Rich, S.J. (2007). Curriculum theory and methods: Perspectives on learning and teaching. Mississauga, ON: John Wiley \& Sons Canada.

19. Westley, F., Zimmerman, B., \& Patton, M.Q. (2007). Getting to maybe. Toronto: Vintage Canada.

20. Heylighen, F., Cilliers, P., \& Gershenson, C. (2007). Philosophy and complexity. In Bogg, J., \& Geyer, R. (Eds.), Complexity, science and society (pp. 117-134). New York: Radcliffe.

21. Gonzalez, M., Coenders, G., Saez, M., \& Casas, F. (2010). Non-linearity, complexity and limited measurement in the relationship between satisfaction with specific life domains and satisfaction with life as a whole. Journal of Happiness Studies, 11,335-352

22. Newell, W.H. (2001). A theory of interdisciplinary studies. Issues in Integrative Studies, 19, 1-25.

23. Kernick, D. (Ed.). (2004). Complexity and healthcare organization: A view from the street. San Francisco: Radcliffe Medical Press.

24. Bleakley, A. (2006). Broadening conceptions of learning in medical education: The message from teamworking. Medical Education, 40(2), 150-157.

25. Weaver, W. (1948). Science and complexity. American Scientist, 32, 536-544.

26. Cilliers, P. (1998). Complexity and postmodernism: Understanding complex systems. London: Routledge.

27. Creswell, J.W. (1998). Qualitative inquiry and research design: Choosing among five traditions. Thousand Oaks, CA: Sage.

28. Hammersley, M., \& Atkinson, P. (1995). Ethnography: Principles in practice, 2nd edition. London: Routledge.

29. Lincoln, Y.S., \& Guba, E.G. (1985). Naturalistic inquiry. Beverley Hills: Sage Publications. 


\section{JRIPE}

120

Complexity science and IPE

Weaver, McMurtry, Conklin, Brajtman, Hall

\section{Journal of Research in Interprofessional Practice and Education}

30. Merriam, S.B. (1988). Case study research in education. San Francisco: Jossey-Bass.

31. Patton, M.Q. (2002). Qualitative research \& evaluation methods, 3rd edition. Thousand Islands, CA: Sage Publications.

32. Loiselle, C.G., Profetto-McGrath, J., Polit, D.F., \& Tatano Beck, C. (2007). Canadian essentials of nursing research, 2nd edition. Philadelphia: Lippincott Williams \& Wilkins.

33. Yin, R.K. (2002). Case study research design and methods, 3rd edition. Thousand Oaks, CA: Sage Publications.

34. Creswell, J.W. (2007). Qualitative inquiry and research design: Choosing among five traditions. Thousand Oaks, CA: Sage Publications.

35. Anderson, R.A., Crabtree, B.F., Steele, D.J., \& McDaniel, R.R. (2005). Case study research: The view from complexity science. Qualitative Health Research, 15(5), 669-685.

36. Bell, I., Caspi, O., Schwartz, G., Grant, K., Gaudet, T. et al. (2002). Integrative medicine and systematic outcomes research: Issues in the emergence of a new model for primary health care. Archives of Internal Medicine, 162, 133-140.

37. Davis, B., \& Simmt, E. (2003). Understanding learning systems: Mathematics education and complexity science. Journal for Research in Mathematics Education, 34(2), 137-167.

38. Surowiecki, J. (2004). The wisdom of crowds: Why the many are smarter than the few and how collective wisdom shapes business, economies, societies and nations. New York: Random House Inc.

39. Watts, D. (2003). Six degrees: The science of a connected age. New York: Norton.

40. D'Amour, D., \& Oandasan, I. (2005). Linking interprofessional education with collaborative practice. Journal of Interprofessional Care, 19(S1), 8-20.

41. Weaver, L., \& Cousins, J.B. (2004). Unpacking the participatory process. Journal of Multidisciplinary Evaluation, 1, 19-40.

42. Barry, D. (1991). Managing the bossless team: Lessons in distributed leadership. Organizational Dynamics, 20, 31-47.

43. Smircich, L., \& Morgan, G. (1982). Leadership: The management of meaning. The Journal of Applied Behavioral Science, 18, 257-273.

44. Solansky, S.T. (2008). Leadership style and team process in self-managed teams. Journal of Leadership \& Organizational Studies, 14, 332-342.

45. Stacey, R.D. (2001). Complex responsive processes in organizations: Learning and knowledge creation. New York: Routledge. 